\title{
ACÚMULO E COMPOSIÇÃO MORFOLÓGICA DO PASTO DE CAPIM- TANZÂNIA ADUBADO COM NITROGÊNIO OU CONSORCIADO COM ESTILOSANTES CAMPO GRANDE
}

\author{
ACCUMULATION AND FORAGE MORPHOLOGICAL COMPOSITION OF \\ TANZANIA GRASS FERTILIZED WITH NITROGEN OR INTERCROPPED WITH \\ CAMPO GRANDE STYLOSANTHES
}

\section{Alyson Andrade PINHEIRO' ${ }^{1}$; Ulysses CECATO ${ }^{2}$; Túlio Otávio Jardim D’Almeida LINS ${ }^{3}$; Tatiane BELONI ${ }^{4}$; Alexandre KRUTZMANN ${ }^{5}$; Bruno Shigueo IWAMOTO ${ }^{6}$; Gracielle Caroline MARI ${ }^{7}$}

1. Pesquisador DCR da EMATER - Goiás, Brasil. jagualyson@bol.com.br; 2. Professor, Doutor, Centro de Ciências Agrárias, Departamento de Zootecnia - Universidade Estadual de Maringá - UEM, Maringá, PR, Brasil; 3. Doutorando em Zootecnia pelo Programa de Pós-graduação em Zootecnia - PPZ, Universidade Estadual do Sudoeste da Bahia, Itapetinga, BA, Brasil; 4. Doutoranda na USP, Escola Superior de Agricultura Luiz de Queiroz - ESALQ, Programa de Pós-Graduação em Ciência Animal e Pastagens, Piracicaba, SP, Brasil; 5. Mestre em Zootecnia pelo PPZ, UEM, Maringá, PR, Brasil; 6. Doutor em Zootecnia pelo PPZ, UEM, Maringá, PR, Brasil; 7. Doutoranda em Zootecnia pelo PPZ, UEM, Maringá, PR, Brasil.

RESUMO: Objetivou-se avaliar o acúmulo de massa de forragem e a composição morfológica do pasto de capim-Tanzânia adubado com nitrogênio ou consorciado com estilosantes Campo Grande. Utilizou-se um delineamento experimental em blocos ao acaso com parcelas subdivididas, com três repetições. Os tratamentos foram constituídos por: Tanzânia + Estilosantes; Tanzânia $+75 \mathrm{~kg} \mathrm{~N}$ ha $^{-1}$; Tanzânia $+150 \mathrm{~kg} \mathrm{~N} \mathrm{ha}^{-1}$; Tanzânia $+225 \mathrm{~kg} \mathrm{~N} \mathrm{ha}^{-1}$. A maior porcentagem de lâmina foliar verde foi observada na primavera e nos pastos com 150 e $225 \mathrm{~kg}$ de N/ha. A porcentagem de colmo+bainha verde foi maior no verão e no outono, assim como, nos pastos adubados com $\mathrm{N}$. A porcentagem de material morto foi mais elevada no outono e inverno. Com a aplicação de $225 \mathrm{~kg}$ de N/ha, os pastos apresentaram maior acúmulo diário de massa de forragem em relação aos outros tratamentos. A circunferência das touceiras foi semelhante entre os pastos consorciados e adubados com N. A quantidade de perfilhos vivos foi maior quando utilizou-se doses mais elevadas de nitrogênio. Os pastos consorciados com estilosantes ou adubados com 75 e $150 \mathrm{~kg}$ de nitrogênio apresentam respostas semelhantes para as características estruturais do pasto, e para o acúmulo de forragem.

PALAVRAS-CHAVE: Colmo. Lâmina foliar. Leguminosa. Perfilho. Ureia.

\section{INTRODUÇÃO}

A produção de forragem é função de fatores inerentes às condições climáticas e de fatores passíveis de serem alterados pelo homem, tais como disponibilidade de nutrientes e de água. Além disso, as técnicas de manejo empregadas podem influir na dinâmica de produção e uso dessa forragem (CECATO et al., 2006). A produtividade da planta forrageira decorre da contínua emissão de folhas e perfilhos, processos importantes para restauração da área foliar após desfolhação e para a perenidade do pasto. O desenvolvimento de folhas é fundamental para o crescimento vegetal, assim como, o de colmos. Segundo Santos et al. (2011), o desenvolvimento de colmos também influencia a produção de forragem porque, dependendo do estádio de desenvolvimento do perfilho, o colmo tem prioridade na partição de fotoassimilados.

As plantas forrageiras variam quanto à estrutura da vegetação, em função da arquitetura da planta, do hábito e estádio de crescimento, das condições edafoclimáticas e do efeito dos animais.
A produtividade e a estrutura do dossel forrageiro podem ser influenciadas pelo manejo e, principalmente, pelas diferentes frequências e intensidade de pastejo de pastejo utilizadas. Tradicionalmente, as pastagens da região noroeste do Paraná são manejadas inadequadamente, o que, associado à sazonalidade climática, determina a distribuição irregular da produção de forragem ao longo do ano. Nessas condições, ocorrem flutuações acentuadas na quantidade de forragem disponível para os animais ao longo das estações que, por sua vez, podem ocasionar variações no desempenho individual e por área. Segundo Cano et al. (2004b), para amenizar essa situação, há a necessidade de se manter o pasto sempre com nível adequado de massa de forragem.

Segundo Barbero et al. (2009) as gramíneas do gênero Panicum apresentam crescimento tipicamente estacional, concentrando sua produção no período da primavera até o início do outono. Mesmo assim, quando o manejo é adequado, gramíneas do gênero Panicum alcançam elevada produtividade, devido à boa capacidade 
fotossintética e à boa resposta à adubação e à irrigação (CUTRIM JUNIOR et al., 2011).

A perenidade e a recuperação de plantas após o corte ou pastejo dá-se pela contínua substituição de perfilhos (BRISKE, 1991). Além da capacidade de perfilhar, outros fatores influenciam a recuperação das plantas após o corte ou pastejo, como: a sobrevivência dos meristemas apicais, o uso dos carboidratos de reserva, a área foliar remanescente e as condições do meio ambiente (MONTEIRO et al., 1996). Entretanto, o perfilhamento depende das condições internas e externas à planta, sendo regulado, principalmente, pelo genótipo, balanço hormonal, florescimento, luz, temperatura, água, nutrição mineral e manejo (RÊGO Et al., 2002).

A quantidade de perfilhos produzidos e a duração de vida dos mesmos variam entre espécies, sendo que algumas perfilham abundantemente e, outras, espaçadamente (GOMIDE; ZAGO, 1980; NASCIMENTO et al., 1980). Outro fator que intensifica o processo de perfilhamento nas gramíneas é a eliminação do meristema apical, cessando, assim, a dominância que este exerce sobre as outras gemas da planta, estimulando o perfilhamento lateral e contribuindo para a recuperação e o aumento na produção da planta (RÊEG et al., 2002).
Objetivou-se avaliar o acúmulo de massa de forragem, composição morfológica e a densidade populacional de perfilhos do pasto de capimTanzânia (Panicum maximum Jacq. cv. Tanzânia-1) adubado com nitrogênio ou consorciado com estilosantes Campo Grande (Stylosanthes ssp).

\section{MATERIAL E MÉTODOS}

O experimento foi conduzido na estância JAE, em Santo Inácio-PR, região noroeste do Paraná. A localização geográfica é $23^{\circ} 25^{\prime} \mathrm{S}$ de latitude e $51^{\circ} 57^{\prime} \mathrm{O}$ de longitude e possui altitude média de 410 metros. O tipo climático predominante na região é o Cfa - subtropical úmido mesotérmico (Köppen), caracterizado pela predominância de verões quentes, baixa frequência de geadas severas e tendência de concentração das chuvas no período do verão, com temperatura média anual de $22,1^{\circ} \mathrm{C}$ e precipitação anual de $1200 \mathrm{~mm}$. O período experimental foi de outubro de 2009 à setembro de 2010 .

Os dados climáticos referentes à precipitação $(\mathrm{mm})$, umidade relativa do ar (\%), temperatura mínima, média e máxima $\left({ }^{\circ} \mathrm{C}\right)$ correspondentes ao período experimental podem ser visualizados na Figura 1.

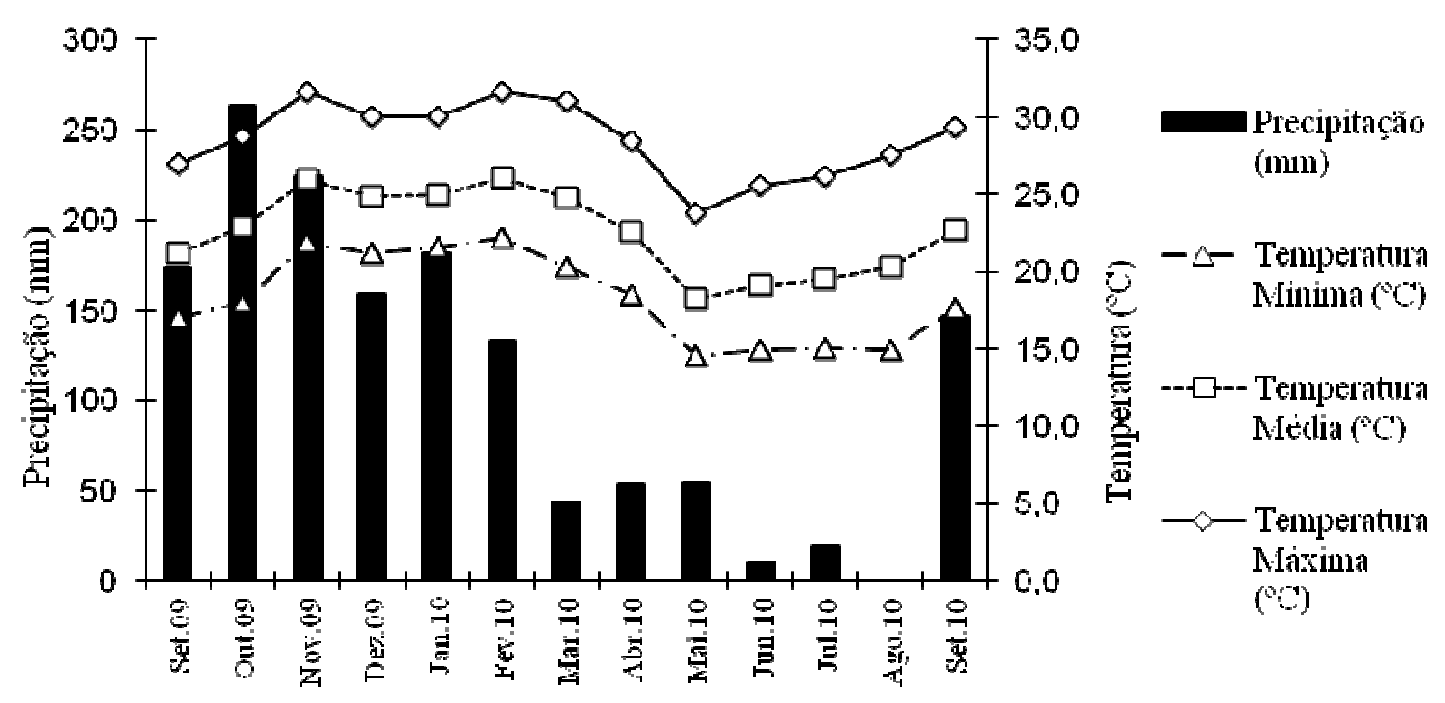

Figura 1 - Dados climaticos observados dnatute o penoilo experimental Fonte: Precipiração: Estancia JAE - Temperatura: IAPAR - Faranavai. PR

O solo da região é o Latossolo Vermelho Escuro Distrófico de textura arenosa (Embrapa, 1999). A composição química do solo no início do período experimental pode ser visualizada na Tabela 1. 
Tabela 1. Composição química do solo da área no início do período experimental $(0-20 \mathrm{~cm}$ de profundidade).

\begin{tabular}{|c|c|c|c|c|c|c|c|c|c|c|c|c|}
\hline \multirow{2}{*}{$\begin{array}{l}\text { TRATA } \\
\text { MENTO }\end{array}$} & \multirow{2}{*}{\multicolumn{2}{|c|}{$\begin{array}{c}\mathrm{pH} \\
\mathrm{CaCl}_{2} \\
\mathrm{H}_{2} \mathrm{O}\end{array}$}} & $\begin{array}{c}\mathrm{Al}_{+}^{3} \\
+\end{array}$ & $\mathrm{H}^{+}+\mathrm{Al}^{3+}$ & $+\mathrm{Ca}^{2+}$ & $\mathrm{Mg}_{+}$ & $\mathrm{K}^{+}$ & SB & $\begin{array}{c}\mathrm{CT} \\
\mathrm{C} \\
\end{array}$ & \multirow{2}{*}{$\underset{3}{\mathrm{mg} \mathrm{dm}}$} & \multirow{2}{*}{$\begin{array}{c}\mathrm{C} \\
\mathrm{g} \mathrm{dm}_{3}^{-}\end{array}$} & \multirow[t]{2}{*}{$\mathrm{V} \%$} \\
\hline & & & & \multicolumn{6}{|c|}{ 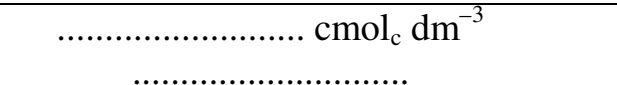 } & & & \\
\hline & & 6,3 & 0,0 & & & & & & & & & \\
\hline Tz + Est. $^{1}$ & 5,40 & $\begin{array}{c}3 \\
6,2\end{array}$ & $\begin{array}{c}0 \\
0,0\end{array}$ & 2,25 & 1,18 & 0,54 & 0,12 & 1,59 & 3,95 & 8,45 & 6,10 & 40,14 \\
\hline 75 kg.N.ha & 5,20 & 0 & 0 & 2,30 & 1,03 & 0,40 & 0,11 & 1,54 & 3,84 & 4,77 & 6,65 & 40,00 \\
\hline 150 & & 6,4 & 0,0 & & & & & & & & & \\
\hline $\begin{array}{l}\text { kg.N.ha } \\
225\end{array}$ & 5,43 & $\begin{array}{c}0 \\
6,3\end{array}$ & $\begin{array}{c}0 \\
0,0\end{array}$ & 2,14 & 1,15 & 0,45 & 0,09 & 1,69 & 3,83 & 7,07 & 5,29 & 41,52 \\
\hline kg.N.ha & 5,40 & 7 & 0 & 2,19 & 1,05 & 0,46 & 0,11 & 1,62 & 3,81 & 8,53 & 6,40 & 42,38 \\
\hline
\end{tabular}

Fonte: Laboratório do Departamento de Agronomia da UEM; ${ }^{1}$ Tanzânia + estilosantes

A área utilizada foi estabelecida em fevereiro de 2008 com capim-Tanzânia (Panicum maximun Jacq. cv. Tanzânia - 1) na forma de monocultura e em consórcio com a leguminosa Estilosantes Campo Grande (80\% Stylosanthes capitata $+20 \%$ Stylosanthes macrocephala) e desde então vem sendo utilizada com os mesmos tratamentos. A área total da pastagem foi de 12 ha, dividida em três blocos e esses por sua vez subdivididos em quatro piquetes (unidades experimentais), perfazendo um total de 12 piquetes de uma hectare. Cada unidade experimental possuía bebedouro com bóia automática e cocho para sal mineral.

Utilizou-se um delineamento experimental em blocos ao acaso com parcelas subdivididas, com três repetições e tendo como tratamentos na parcelas: Tanzânia + Estilosantes; Tanzânia + $75 \mathrm{~kg}$ $\mathrm{N} \mathrm{ha}^{-1}$; Tanzânia $+150 \mathrm{~kg} \mathrm{~N} \mathrm{ha}^{-1}$; Tanzânia +225 $\mathrm{kg} \mathrm{N} \mathrm{ha}{ }^{-1}$. Nas subparcelas foram avaliados os períodos, considerando-se como primavera (3 de outubro de 2009 à 19 de dezembro de 2009), verão (20 de dezembro de 2009 à 13 de março de 2010), outono (14 de março de 2010 à 8 de maio de 2010) e inverno ( 9 de maio de 2010 à 25 de setembro de 2010).

Antes do início do experimento (setembro/2009), com base na análise do solo apresentada na Tabela 1, realizou-se a calagem do solo (calcário dolomítico), a fim de elevar a saturação por bases para $70 \%$, segundo Werner et al. (1996). A adubação fosfatada foi realizada em uma única aplicação, setembro de 2009, sendo a fonte de fósforo utilizada o super fosfato simples $\left(60 \mathrm{~kg} \mathrm{P}_{2} \mathrm{O}_{5}\right.$ $\left.\mathrm{ha}^{-1}\right)$. As adubações nitrogenadas $(75,150$ e 225 $\mathrm{kg} / \mathrm{ha})$ e potássica $\left(60 \mathrm{~kg} \mathrm{~K}_{2} \mathrm{O} \mathrm{ha}{ }^{-1}\right)$ foram realizadas a lanço, em três aplicações: 26 de outubro de 2009,
8 de janeiro de 2010 e 24 de março de 2010. Foram utilizados uréia e nitrato de amônio como fonte de nitrogênio e cloreto de potássio como fonte de potássio.

O pasto foi manejado pelo método de lotação contínua e taxa de lotação variável, mantendo-se a altura do pasto entre 45 e $50 \mathrm{~cm}$. A altura média do pasto foi medida semanalmente, utilizando-se uma régua, avaliando 50 pontos por piquete (Figura 2).

Para a manutenção da altura e manejo do pasto foram utilizados novilhos da raça Nelore com peso corporal de $230 \pm 9 \mathrm{~kg}$ (animais testadores). Cada piquete possuía três animais testadores e animais reguladores que eram colocados ou retirados dos piquetes em função da altura da pastagem, conforme o método "put and take" (MOTT; LUCAS, 1952). Uma área adjacente à experimental, com a mesma gramínea, foi disponibilizada para manutenção dos animais reguladores.

No inicio do experimento, os animais foram tratados com Ivermectina $1 \%$ para controle de endoparasitos e ectoparasitos. Foi fornecido aos animais suplemento mineral comercial.

O acúmulo diário de massa de forragem (ADMF) foi avaliado a cada 28 dias, utilizando-se três gaiolas de exclusão com área de $1 \mathrm{~m}^{2}$ cada, por piquete, por meio da técnica de amostragem do triplo emparelhamento (Moraes et al., 1990). Para o cálculo da taxa de acúmulo diário, utilizou-se a equação descrita por Campbell, (1966). O material coletado foi seco em estufa a $55^{\circ} \mathrm{C}$ (ventilação forçada) por 72 horas. Os valores de massa de forragem foram convertidos para $\mathrm{kg} / \mathrm{ha}$ de MS. 


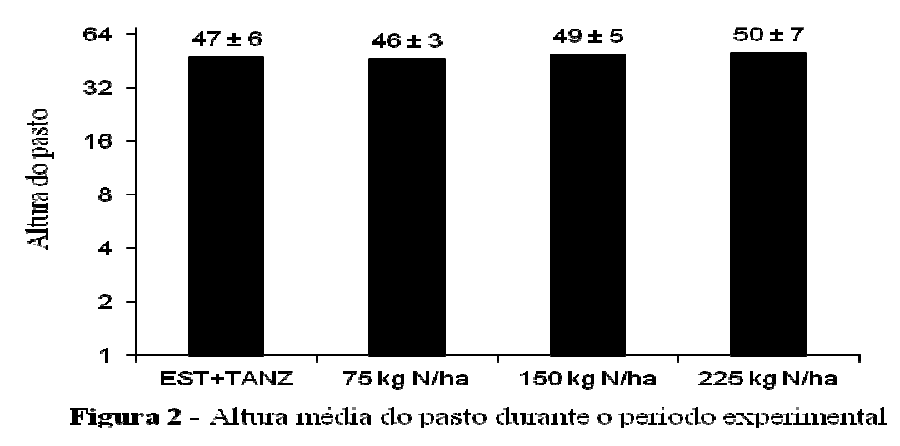

As avaliações dos componentes morfológicos da forragem foram realizadas a cada 28 dias. A coleta do material foi realizada pelo método da dupla amostragem descrito por Gardner (1986). Realizaram-se 15 avaliações por piquete, sendo 10 estimativas visuais e cinco reais (cortes) a $5 \mathrm{~cm}$ do solo, ao acaso utilizando-se um quadrado com área de $1 \mathrm{~m}^{2}$. Do material coletado, uma subamostra foi retirada e separada nas seguintes frações: lâmina foliar verde (LFV), colmo+bainha (CBV), material morto (MM) e Estilosantes (ES planta inteira). Os materiais pertencentes às diferentes frações foram secos em estufa a $55^{\circ} \mathrm{C}$ (ventilação forçada) por 72 horas. Os valores de massa de forragem foram convertidos para $\mathrm{kg} / \mathrm{ha}$ de MS e os componentes morfológicos expressos em proporção (\%) da massa de forragem.

Ao final do verão foram realizadas avaliações para determinar o perímetro médio das touceiras existentes nos piquetes, que foram escolhidas aleatoriamente, porém representativas da área. Para realizar a medida, usou-se uma fita métrica e contornou a base da touceira. Para estimar a densidade populacional de perfilhos foram coletadas quatro touceiras representativas de cada unidade experimental, totalizando doze touceiras por tratamento. As touceiras foram cortadas rente ao solo e, em seguida foram levadas para o Laboratório de Alimentação e Nutrição Animal-DZO/UEM onde fez-se a separação e contagem dos perfilhos vivos e mortos.

A análise da variância foi realizada com o auxílio do programa Sistema de Análises Estatísticas e Genéticas / SAEG (Ribeiro Jr., 2001), segundo o modelo:

$$
\mathbf{Y}_{\mathrm{ijk}}=\boldsymbol{\mu}+\mathbf{T}_{\mathrm{i}}+\mathbf{P}_{\mathrm{j}}+\mathbf{B}_{\mathrm{k}}+\mathbf{T} \mathbf{P}_{\mathrm{ij}}+\mathbf{e}_{\mathrm{ijk}}
$$

Onde, Yijk = valor da variável observada no piquete que recebeu o tratamento $i$, coletada no período $\mathrm{j}$ e encontrava-se no bloco $\mathrm{k} ; \mu=$ média geral; $\mathrm{Ti}$ = efeito do tratamento, com $\mathrm{i}$ variando de 1 a $4 ; \mathrm{Pj}=$ efeito devido ao período, com $\mathrm{j}$ variando de 1 a $4 ; \mathrm{Bk}=$ efeito devido ao bloco, com $\mathrm{k}$ variando de 1 a 3; TPij= é o efeito da interação entre tratamento e período; eijk = erro aleatório associado a cada observação. As médias foram submetidas ao teste Tukey a $5 \%$ de probabilidade.

\section{RESULTADOS E DISCUSSÃO}

$\mathrm{Na}$ avaliação da composição morfológica não foi observado interação $(\mathrm{P}>0,05)$ entre os pastos consorciados ou adubado com $\mathrm{N}$ e as estações (Tabela 2). Independente do consórcio com estilosantes ou das doses de $\mathrm{N}$ utilizadas, a porcentagem de lâmina foliar verde (LFV) foi o componente morfológico com maior participação na forragem produzida.

A maior porcentagem de LFV observada na primavera e nos pastos adubados com 150 e $225 \mathrm{~kg}$ de N/ha, possivelmente, deve-se ao fato dos bons índices climáticos na estação (Figura 1), ou provavelmente também pela maior assimilação do $\mathrm{N}$ aplicado nas plantas. Basso et al. (2010) afirmam que o $\mathrm{N}$ está diretamente relacionado com o aumento do aparecimento de folhas. Outro fator importante a ser levado em consideração é que, quanto maior for a proporção de folha no sistema, melhor será o consumo e, conseqüentemente o desempenho animal, já que a mesma é a principal fração da planta buscado pelo animal no pasto.

A porcentagem de colmo+bainha verde (CBV) foi maior no verão e no outono, assim como, nos pastos adubados com $\mathrm{N}$.

A maior produção de $\mathrm{CBV}$ pode estar associada à aplicação do $\mathrm{N}$ e às favoráveis condições climáticas nas estações ocorridas no período (Figura 1), uma vez que o nitrogênio em condições de temperatura e umidade adequadas acelera o crescimento estrutural das plantas como um todo. Cecato et al. (2000) afirmaram que a aplicação de $\mathrm{N}$ promove na planta aumento dos constituintes celulares e do vigor de rebrota, resultando assim, na melhoria da produção de lâminas foliares e de colmos, fato esse ocorrido no presente estudo. Porém, a produção excessiva de colmo pode ter efeito negativo na nutrição animal, 
uma vez que, bovinos em pastejo preferem folhas a

2001).

colmos e materiais senescentes (Carvalho et al.,

Tabela 2. Composição morfológica do capim-Tanzânia e composição botânica da pastagem consorciada ou adubada com nitrogênio nas estações do ano.

\begin{tabular}{|c|c|c|c|c|c|}
\hline \multirow{3}{*}{ Períodos } & \multicolumn{4}{|c|}{ Tratamento } & \multirow{3}{*}{ Geral } \\
\hline & Estilosantes & $75 \mathrm{~kg}$ de $\mathrm{N}$ & $150 \mathrm{~kg}$ de $\mathrm{N}$ & $225 \mathrm{~kg} \mathrm{de} \mathrm{N}$ & \\
\hline & \multicolumn{4}{|c|}{ \% Lâmina foliar verde } & \\
\hline Primavera & $50 \pm 2 *$ & $58 \pm 7$ & $64 \pm 2$ & $58 \pm 6$ & $58 \mathrm{~A}$ \\
\hline Verão & $34 \pm 1$ & $42 \pm 3$ & $46 \pm 8$ & $45 \pm 3$ & $42 \mathrm{~B}$ \\
\hline Outono & $31 \pm 2$ & $36 \pm 1$ & $41 \pm 3$ & $40 \pm 2$ & $37 \mathrm{~B}$ \\
\hline Inverno & $35 \pm 10$ & $37 \pm 2$ & $49 \pm 7$ & $47 \pm 6$ & $42 \mathrm{~B}$ \\
\hline \multirow[t]{2}{*}{ Média } & $37 \mathrm{c}$ & $43 \mathrm{~b}$ & $50 \mathrm{a}$ & $47 \mathrm{ab}$ & \\
\hline & \multicolumn{4}{|c|}{$\%$ Colmo + bainha verde } & \\
\hline Primavera & $16 \pm 3$ & $20 \pm 2$ & $21 \pm 1$ & $23 \pm 5$ & $20 \mathrm{~B}$ \\
\hline Verão & $33 \pm 5$ & $33 \pm 3$ & $34 \pm 6$ & $37 \pm 3$ & $34 \mathrm{~A}$ \\
\hline Outono & $29 \pm 2$ & $32 \pm 2$ & $33 \pm 5$ & $36 \pm 3$ & $32 \mathrm{~A}$ \\
\hline Inverno & $19 \pm 3$ & $22 \pm 4$ & $24 \pm 4$ & $20 \pm 5$ & $21 \mathrm{~B}$ \\
\hline \multirow[t]{2}{*}{ Média } & $24 \mathrm{~b}$ & $27 \mathrm{ab}$ & $28 \mathrm{ab}$ & $29 \mathrm{a}$ & \\
\hline & \multicolumn{4}{|c|}{$\%$ Material morto } & \\
\hline Primavera & $17 \pm 2$ & $22 \pm 5$ & $14 \pm 2$ & $18 \pm 1$ & $18 \mathrm{C}$ \\
\hline Verão & $22 \pm 1$ & $24 \pm 5$ & $19 \pm 6$ & $18 \pm 3$ & $21 \mathrm{C}$ \\
\hline Outono & $26 \pm 5$ & $32 \pm 3$ & $25 \pm 4$ & $24 \pm 3$ & $27 \mathrm{~B}$ \\
\hline Inverno & $28 \pm 7$ & $41 \pm 6$ & $27 \pm 3$ & $33 \pm 4$ & $33 \mathrm{~A}$ \\
\hline \multirow[t]{2}{*}{ Média } & $23 \mathrm{~b}$ & $30 \mathrm{a}$ & $22 \mathrm{~b}$ & $23 \mathrm{~b}$ & \\
\hline & \multicolumn{4}{|c|}{ \% Estilosantes } & \\
\hline Primavera & $17 \pm 1$ & --- & --- & --- & 17 \\
\hline Verão & $11 \pm 3$ & --- & --- & --- & 11 \\
\hline Outono & $14 \pm 7$ & --- & --- & --- & 14 \\
\hline Inverno & $17 \pm 10$ & --- & --- & --- & 17 \\
\hline Média & 14 & --- & --- & --- & \\
\hline
\end{tabular}

Letras iguais, maiúscula nas colunas e minúsculas nas linhas, não diferem pelo teste Tukey $(\mathrm{P}<0,05)$; *Desvio padrão da média.

A porcentagem de material morto (MM) na primavera e no verão foi inferior as demais estações. Isso demonstra que no período chuvoso a renovação de tecidos é acentuada, e tanto a sobrevivência quanto a mortalidade de perfilhos é acelerada (Moreira et al, 2009). Sendo assim, no final do período chuvoso há maior tendência de acúmulo de material senescente e morto, já que a capacidade de renovação de folhas e perfilhos passam a ser limitada pelas condições ambientais (Figura 1). Com isso, é possível justificar a maior proporção de MM no inverno do presente estudo.

No consórcio com estilosantes ocorreu a mesma porcentagem de MM que nos pastos adubados com 150 e $225 \mathrm{~kg}$ de N/ha, demonstrando assim, que o processo gradativo de liberação de $\mathrm{N}$ pelo consórcio propiciou maior estabilidade ao pasto, reduzindo o sombreamento e, conseqüentemente as perdas de folhas por senescência e morte de forma semelhante aos adubados com maior quantidade de nitrogênio. Fato esse que não aconteceu quando as plantas foram adubadas com $75 \mathrm{~kg}$ de N/ha, onde houve maior \% de MM.

Não houve diferença entre as estações para porcentagem de estilosantes na composição botânica do pasto. Mesmo sendo inferiores as gramíneas quanto à adaptação a solos de baixa fertilidade, o estilosantes se mostra competitivo no sistema, provavelmente, por ser uma leguminosa de clima tropical.

Com a aplicação de $225 \mathrm{~kg}$ de N/ha, os pastos apresentaram maior acúmulo diário de massa de forragem (ADMF) em relação aos outros tratamentos (Tabela 3). 
Tabela 3. Acúmulo diário e produção total de massa de forragem em capim-Tanzânia consorciado ou adubado com doses nitrogênio (N) nas estações do ano.

\begin{tabular}{|c|c|c|c|c|c|}
\hline \multirow{3}{*}{ Períodos } & & Tra & ento & & \multirow{3}{*}{ Média } \\
\hline & Estilosantes & $75 \mathrm{~kg}$ de $\mathrm{N}$ & $150 \mathrm{~kg}$ de $\mathrm{N}$ & $225 \mathrm{~kg}$ de $\mathrm{N}$ & \\
\hline & \multicolumn{4}{|c|}{ Acúmulo diário de massa de forragem $(\mathrm{kg} / \mathrm{ha} / \mathrm{dia})$} & \\
\hline Primavera & $45 \pm 6^{*}$ & $46 \pm 8$ & $62 \pm 18$ & $72 \pm 14$ & $56 \mathrm{AB}$ \\
\hline Verão & $64 \pm 17$ & $63 \pm 17$ & $63 \pm 15$ & $91 \pm 3$ & $70 \mathrm{~A}$ \\
\hline Outono & $34 \pm 6$ & $43 \pm 2$ & $46 \pm 17$ & $66 \pm 8$ & $47 \mathrm{AB}$ \\
\hline Inverno & $18 \pm 3$ & $29 \pm 4$ & $32 \pm 6$ & $39 \pm 1$ & $30 \mathrm{~B}$ \\
\hline Média & $40 \mathrm{~b}$ & $45 \mathrm{~b}$ & $51 \mathrm{~b}$ & $66 \mathrm{a}$ & \\
\hline Produção total ${ }^{1}$ & $17602 \mathrm{~b}$ & $19058 \mathrm{~b}$ & $20967 \mathrm{~b}$ & $26807 \mathrm{a}$ & \\
\hline
\end{tabular}

Isto ocorreu pelo efeito da adubação nitrogenada quando associada às condições favoráveis de umidade, temperatura e luminosidade (Figura 1). Segundo Cano et al. (2004a), os pastos de capim-Tanzânia, em regime de lotação contínua usadas em alturas do pasto entre 20 e $80 \mathrm{~cm}$, permitem quantidades elevadas de taxas de acúmulo de matéria seca. Porém, cuidados devem ser tomados quando feito essas avaliações, pois segundo Parsons et al. (1984), o número de dias usado para a estimativa da taxa de acúmulo de MS pode ocasionar valores subestimados ou superestimados, em decorrência da evolução do índice de área foliar, no interior das gaiolas de exclusão do pastejo.

Por outro lado, os pastos que receberam doses de 75 e $150 \mathrm{~kg} / \mathrm{ha}$ tiveram ADMF semelhante ao consórcio com estilosantes. Esses resultados confirmam assim, os escritos na literatura (BARBERO et al., 2010; Barcellos et al., 2008) de que o uso de leguminosas, pela fixação biológica de $\mathrm{N}$ torna o consórcio uma atividade importante, uma vez que, a mesma recicla o nitrogênio e repassa para a gramínea, e que em boas condições de manejo a resposta das leguminosas para produção de massa de forragem pode se equivaler até a aplicação de $100 \mathrm{~kg}$ de N/ha ao pasto (Paris et al., 2009). Ainda Pizarro, (2001) e Paciullo et al. (2003), relatam que o consórcio de gramíneas com leguminosas diversifica a dieta oferecida ao animal, que por sua vez tende melhorar seu desempenho.

Para as estações o acúmulo diário de massa de forragem foi maior no verão, certamente, as principais causas são as boas condições climáticas ocorridas naquele período (Figura 1). Outro fator que pode ter influenciado nesses resultados foi $o$ aumento da quantidade de horas/luz/dia durante o verão, acarretando em um possível aumento do processo de fotossíntese das plantas e, consequentemente melhorando a produção de massa. Entretanto, no inverno, o ADMF foi menor que o verão e semelhante as demais estações. Isto, certamente foi devido às baixas temperaturas e a quase ausência de chuvas que são comuns nessa estação (Figura 1). Diante de tais circunstâncias, mesmo que haja boa intensidade luminosa às plantas, a falta de água e temperatura adequada diminui o processo fotossintético, proporcionando baixa produção de massa de forragem (BARBERO et al., 2010; Paris et al., 2009; LENZI et al., 2009).

$\mathrm{O}$ perímetro das touceiras foi semelhante entre os pastos consorciados e os adubados com $\mathrm{N}$ (Tabela 4).

Os valores encontrados neste experimento são inferiores daqueles obtidos por Montagner (2007), porém, trabalhando com capim-Mombaça em pastejo com lotação intermitente e diferentes alturas de manejo, que obteve o perímetro das touceiras de $140 \mathrm{~cm}$, em média.

A quantidade de perfilhos vivos foram maiores quando se utilizou doses mais elevadas de nitrogênio, confirmando assim, os relatos de Lemaire \& Champman (1996) quando afirmaram que o uso de nitrogênio tem relação direta com a taxa de aparecimento de perfilhos. Garcez Neto et al. (2002) verificaram efeito expressivo do suprimento de $\mathrm{N}$ no número total de perfilhos (21\% na densidade populacional de perfilhos). Esses autores relatam que o perfilhamento em gramíneas é uma característica estrutural determinante da plasticidade morfogênica das plantas forrageiras influenciada por combinações de fatores nutricionais, ambientais e de manejo. 
Tabela 4. Perímetro das touceiras e número de perfilhos por touceiras em capim-Tanzânia consorciado ou adubado com doses de nitrogênio $(\mathrm{N})$

\begin{tabular}{|c|c|c|c|c|c|}
\hline & \multicolumn{4}{|c|}{ Tratamento } & \multirow{2}{*}{ Média } \\
\hline & Estilosantes & $75 \mathrm{~kg}$ de $\mathrm{N}$ & $150 \mathrm{~kg}$ de $\mathrm{N}$ & $225 \mathrm{~kg}$ de N & \\
\hline Medida touceira $(\mathrm{cm})$ & $94 \pm 6^{*}$ & $85 \pm 2$ & $101 \pm 23$ & $96 \pm 16$ & 94 \\
\hline Perfilhos vivos & $121 \pm 11 b$ & $135 \pm 31 b$ & $154 \pm 17 \mathrm{ab}$ & $175 \pm 21 \mathrm{a}$ & 146 \\
\hline Perfilhos mortos & $37 \pm 17$ & $33 \pm 13$ & $26 \pm 3$ & $37 \pm 6$ & 33 \\
\hline Total de Perfilhos & 158 & 168 & 180 & 212 & 179 \\
\hline
\end{tabular}

A igualdade entre o número de perfilhos mortos no presente estudo é um indicador de que o manejo do pasto foi realizado de maneira adequada, pois sabe-se, que o pastejo intensivo causa morte acelerada dos perfilhos.

\section{CONCLUSÕES}

Os pastos consorciados com estilosantes ou adubados com 75 e $150 \mathrm{~kg}$ de nitrogênio apresentam respostas semelhantes para as características estruturais do pasto, e também para o acúmulo da forragem.

As estações do ano influenciam diretamente no acúmulo de forragem e na composição de folhas do pasto.

$\mathrm{Na}$ dose maior de nitrogênio (225 kg/ha) o pasto apresenta maior percentagem de lâminas foliares.

\begin{abstract}
The objective was to evaluate the accumulation of forage yield, composition and morphology of Tanzania grass pastures (Panicum maximum Jacq. cv. Tanzania-1) fertilized with nitrogen or intercropped with Campo Grande Stylosanthes. Were used a randomized blocks with split plots with three replications and having treatments as main plots: Stylosanthes + Tanzania; Tanzania $+75 \mathrm{~kg} \mathrm{~N}$ ha-1; Tanzania $+150 \mathrm{~kg} \mathrm{~N}$ ha-1; Tanzania $+225 \mathrm{~kg} \mathrm{~N}$ ha-1 and the subplots seasons. The highest percentage of green leaf blade were observed in spring and the pastures with 150 and $225 \mathrm{~kg} \mathrm{~N} / \mathrm{ha}$. The percentage of green stem + sheath were higher in summer and autumn, as well as in pastures fertilized with N. The percentage of dead material was higher in autumn and winter. With the application of $225 \mathrm{~kg} \mathrm{~N} / \mathrm{ha}$, pastures had higher daily accumulation of dry matter in relation to other treatments. The circumference of the stools was similar between the consortium and pastures fertilized with $\mathrm{N}$. The number of live tillers was higher when we used higher doses of nitrogen. Pastures intercropped with stylosanthes or nitrogen fertilized (75 and $150 \mathrm{~kg}$ ) presents better morphology and daily accumulation of forage.
\end{abstract}

KEYWORDS: Stem. Forage crops. Leaf blade. Legume. Nitrate. Urea.

\title{
REFERÊNCIAS
}

BARBERO, L. M.; CECATO, U.; LUGÃO, S. M. B.; GOME, J. A. N.; LIMÃO, V. A.; ABRAHÃO, J. J. S.; ROMA, C. F. C. Produção animal e valor nutritivo da forragem de pastagem de coastcross consorciada com amendoim forrageiro. Arquivo Brasileiro de Medicina Veterinária e Zootecnia, Belo Horizonte, v. 62, n. 3 , p. 645-653, 2010. http://dx.doi.org/10.1590/S0102-09352010000300021

BARBERO, L. M.; CECATO, U.; ZEOULA, L. M.; DAMASCENO, J. C.; RODRIGUES, A. M.; GOMES, J. A. N. Degradabilidade in situ de estratos de capim-Mombaça adubado com diferentes fontes de fósforo, em pastejo. Acta Scientiarum. Animal Sciences, Maringá, v. 31, n. 1, p. 1-6, 2009.

BARCELLOS, A. O.; RAMOS, A. K. B.; VILELA, L.; MARTHA JÚNIOR, G. B. Sustentabilidade da produção animal baseada em pastagens consorciadas e no emprego de leguminosas exclusivas, na forma de banco de proteína, nos trópicos brasileiros. Revista Brasileira de Zootecnia, Viçosa, v. 37, p.51-67, 2008.

BASSO, K. C.; CECATO, U.; LUGÃO, S. M. B.; GOMES, J. A. N.; BARBERO, L.M.; MOURÃO, G.B. Morfogênese e dinâmica do perfilhamento em pastos de Panicum maximum Jacq. cv. IPR-86 Milênio submetido a doses crescentes de nitrogênio. Revista Brasileira de Saúde e Produção Animal, Salvador, v. 11, n. 4, p. 976-989, 2010. 
BRISKE, D. D. Developmental morphology and physiology of grasses. In: HUTSCHMIDE, R.K.; STUTHRED, J.W. (Eds.). Grazing management an ecological perspective. 1.ed. Portland: Timber Press, 1991. p. 85-108.

CAMPBELL, A. G. Grazed pastures parameters. I. Pasture drymatter production and availability in a stocking rate and grazing management experiment with dairy cows. Journal of Agricultural Science, Cambridge, v. 67, p. 211-216, 1966. http://dx.doi.org/10.1017/S0021859600068295

CANO, C. C. P.; CECATO, U.; CANTO, M. W.; RODRIGUES, A. B.; JOBIM, C. C.; RODRIGUES, A. M.; GALBEIRO, S.; NASCIMENTO, W. G. do. Produção de forragem do capim-Tanzânia (Panicum maximum Jacq. cv. Tanzânia-1) pastejado em diferentes alturas. Revista Brasileira de Zootecnia, Viçosa, v. 33, n. 6, p. 1949-1958, 2004a.

CANO, C.C.P.; CECATO, U.; CANTO, M.W. do.; SANTOS, G.T. dos; GALBEIRO, S.; MARTINS, E.N.; MIRA, R.T. Valor nutritivo do capim-Tanzânia (Panicum maximum Jacq. cv. Tanzânia-1) pastejado em diferentes alturas. Revista Brasileira de Zootecnia, Viçosa, v. 33, n. 6, p. 1959-1968, 2004b.

CARVALHO, P. C. F.; RIBEIRO FILHO, H. M. N.; POLI, C. H. E. C. Importância da estrutura da pastagem na ingestão e seleção de dietas pelo animal em pastejo. In: MATTOS, W.R.S. (Eds) A PRODUÇÃO ANIMAL NA VISÃO DOS BRASILEIROS - REUNIÃO ANUAL DA SOCIEDADE BRASILEIRA DE ZOOTECNIA, 2001, Piracicaba, Anais... Piracicaba, Sociedade Brasileira de Zootecnia, 2001, p. 853-871.

CECATO, U.; GALBEIRO, S.; GOMES, J. A. N. Utilização e manejo de pastos de Panicum e Brachiaria em sistemas pecuários. In: BRANCO, A.F; Dos SANTOS, G.T.; JOBIM, C.C.; et al. (Eds.) Sustentabilidade em sistemas pecuários - 2006, Maringá. p. 147-178.

CECATO, U.; MACHADO, A. O.; MARTINS, E. N.; PEREIRA, L. A. F.; BARBOSA, M. A. A. F.;

SANTOS, G. T. Avaliação da produção e de algumas características da rebrota de cultivares e acessos de Panicum maximum Jacq. sob duas alturas de corte. Revista Brasileira de Zootecnia, Viçosa, v. 29, n. 3, p. 660-668, 2000.

EMPRESA BRASILEIRA DE PESQUISA AGROPECUÁRIA - EMBRAPA. Sistema brasileiro de classificação de solos. Centro nacional de Pesquisa de Solos. Brasília, 1999. 412p.

GARCEZ NETO, A. F.; NASCIMENTO JR., D.; REGAZZI, A. J.; FONSECA, D. M. da.; MOSQUIM, P. R.; GOBBI, K. F. Respostas morfogênicas e estruturais de Panicum maximum cv. Mombaça sob diferentes níveis de adubação nitrogenada e alturas de corte. Revista Brasileira de Zootecnia, Viçosa, v. 31, n. 5, p. 1890-1900, 2002.

GARDNER, A. L. Técnicas de pesquisa em pastagens e aplicabilidade de resultados em sistemas de produção. Brasília: IICA, 197 p. 1986.

GOMIDE, J. A.; ZAGO, C. P. Crescimento e recuperação do capim colonião após o corte. Revista Brasileira de Zootecnia, Viçosa, v. 9, n. 2, p. 293-305, 1980.

CUTRIM-JUNIOR, J. A. A.; CÂNDIDO, M. J. D.; VALENTE, B. S. M.; CARNEIRO, M. S. S.; CARNEIRO, H. A. V. Características estruturais do dossel de capim-Tanzânia submetido a três frequências de desfolhação e dois resíduos pós-pastejo. Revista Brasileira de Zootecnia, Viçosa, v. 40, n. 3, p. 489-497, 2011.

LEMAIRE, G., CHAPMAN, D. Tissue flows in grazed plant communities. In: HODGSON, J.; ILLIUS, A.W. (Ed.) The ecology and management of grazing systems. Wallingford: CAB International, 1996. p. 3-36.

LENZI, A.; CECATO, U.; MACHADO-FILHO L. C. P.; GASPARINO, E.; ROMA, C. F. C.; BARBERO, L. M.; LIMÃO, V. A. Produção e qualidade do pasto de coastcross consorciado ou não com amendoim forrageiro com ou sem aplicação de nitrogênio. Arquivo Brasileiro de Medicina Veterinária e Zootecnia, Belo Horizonte, v. 61, n. 4, p. 918-926, 2009. http://dx.doi.org/10.1590/S0102-09352009000400021 
MONTAGNER, D. B. Morfogênese e acúmulo de forragem em capim - mombaça submetido a intensidades de pastejo rotativo. 2007.60f. Tese (Doutorado em Zootecnia) - Universidade Federal de Viçosa, Viçosa - MG.

MONTEIRO, A. L. G.; MORAES, A. Fisiologia e morfologia de plantas forrageiras. In: MONTEIRO, A.L.G.; MOARES, A. et al. Forragicultura no Paraná. 1.ed. Londrina: CPAF, 1996. p. 75-93.

MORAES, A. de.; MOOJEN, E. L.; MARASCHIN, G. E. Comparação de métodos de estimativa de taxas de crescimento em uma pastagem submetida a diferentes pressões de pastejo. In: REUNIÃO ANUAL DA SOCIEDADE BRASILEIRA DE ZOOTECNIA, 27., 1990, Campinas. Anais... Campinas: SBZ, 1990. p. 332.

MOREIRA, L. de M.; Martuscello, J. A.; Fonseca, D. M. Perfilhamento, acúmulo de forragem e composição bromatológica do capim-braquiária adubado com nitrogênio. Revista Brasileira de Zootecnia, Viçosa, v. 38, n. 9, p. 1675-1684, 2009.

MOTT, G. O.; LUCAS, H. L. The design, conduct and interpretation of grazing trials on cultivated and improved pastures. In: INTERNATIONAL GRASSLAND CONGRESS, 6., Pasadena, 1952.

Proceedings...Pasadena, 1952. P. 1380 - 1385.

NASCIMENTO, M. P. S. B.; NASCIMENTO, H. T. S.; GOMIDE, J. A. Alguns aspectos morfofisiológicos de três gramíneas de clima tropical. Revista Brasileira de Zootecnia, Viçosa, v. 9, n. 1, p. 142-158, 1980.

PACIULLO, D. S. C.; AROEIRA, L. J. M.; ALVIM, M. J.; CARVALHO, M. M. Características produtivas e qualitativas de pastagem de braquiária em monocultivo e consorciada com estilosantes. Pesquisa

Agropecuária Brasileira, Brasília, v. 38, n. 3, p. 421-426, 2003. http://dx.doi.org/10.1590/S0100204X2003000300012

PARIS, W.; CECATO, U.; BRANCO, A. F.; BARBERO, L. M.; GALBEIRO, S. Produção de novilhas de corte em pastagem de Coastcross-1 consorciada com Arachis pintoi com e sem adubação nitrogenada. Revista Brasileira de Zootecnia, Viçosa, v. 38, n. 1, p. 122-129, 2009.

PARSONS, A. J.; COLLETT, B.; LEWIS, J. Changes in the structure and physiology of a perennial ryegrass sward when released from a continuous stocking management: implications for the use of exclusion cages in continuously stocked swards. Grass and Forage Science, Malden, v. 39, p. 1-9, 1984.

http://dx.doi.org/10.1111/j.1365-2494.1984.tb01658.x

PIZARRO, E. A. Novel grasses and legumes germplasm: Advances and perspectives for tropical zones. In: INTERNATIONAL GRASSLAND CONGRESS, 19., 2001, Piracicaba. Proceedings... Piracicaba, 2001. (CDROM).

RÊGO, F. C. A.; CECATO, U.; CANTO, M. W. MARTINS, E.N.; SANTOS, G.T. dos; CANO, C.P.; PETERNELLI, M. Características Morfológicas e Índice de Área Foliar do Capim-Tanzânia (Panicum maximum Jacq. cv. Tanzânia-1) Manejado em Diferentes Alturas, sob Pastejo. Revista Brasileira de Zootecnia, Viçosa v. 31, n. 5, p. 1931-1937, 2002.

RIBEIRO JR., J. Análises estatísticas no SAEG - Sistema de análises estatísticas e genéticas. Versão 8.1. Viçosa, UFV, 2001. 301p.

SANTOS, M. E. R.; FONSECA, D. M.; BRAZ, T. G. S.; SILVA, G. P.; GOMES, V. M.; SILVA, S. P. Influência da localização das fezes nas características morfogênicas e estruturais e no acúmulo de forragem em pastos de capim-braquiária. Revista Brasileira de Zootecnia, Viçosa, v. 40, n. 1, p. 31-38, 2011.

WERNER, J. C.; PAULINO, V. T.; CANTARELLA, H. In: FORRAGEIRAS - RECOMENDAÇÕES DE ADUBAÇÃO E CALAGEM PARA O ESTADO DE SÃO PAULO, 2ed. Campinas, Instituto Agronômico e Fundação IAC, 1996. (Boletim técnico, 100) p. 263. 